\title{
Albendazole and Mebendazole as an Alternative Therapeutic Agent for Adult Giardiasis
}

\author{
Seyyed Javad Hosseini Shokouh and Mossa Ahmadi* \\ Infectious Diseases Research Center, AJA Univercity of Medical Sciences, Tehran, IR Iran. \\ http://dx.doi.org/10.13005/bbra/2121
}

(Received: 20 April 2016; accepted: 02 June 2016)

\begin{abstract}
We examined the therapeutic effects of albendazole. metronidazole and mebenazole 183 patients with giardiasis in Tehran Province. Patients were randomized to receive albendazole $(400 \mathrm{mg}$, once daily for 5 days) or metronidazole $(250 \mathrm{mg}, 3$ times a day for 5 days) or mebendazole $(200 \mathrm{mg}, 2$ times a day for 5 days) . Demographic data of the patients, results of stool exa-mination for Giardia (cyst or trophozoites ) before and after treatment, and drug side $[$ ffects were recorded. The final results showed that albendazole (93\%) and mebendazole ( $89 \%$ ) and metronidazole $(95.5 \%)$ have similar therapeutic effects on giardiasis . Patients in the albendazole group(19.7\%) had fewer side effects compared with metronidazole $(39 \%)$ \& mebendazole groups $(27 \%)$. This difference is statistically significant $(p<0.01)$. We offer the albendazole as a grug of choice of giardiasis.
\end{abstract}

Key words : Albendazole, Mebendazole , Metronidazole , Giardiasis, Therapy.

Giardia lamblia, also known as Giardia duodenalis or Giardia intestinalis, is one of the most common intestinal parasites world-wide and is a frequent cause of diarrhoeal illness ${ }^{1-3}$. It is estimated that about 300 million people annually are affected with the parasite all around the world and it is an important cause of morbidity in the developing world ${ }^{2,3}$.

Many drugs, including metronidazole and albendazole, mebendazole, furazolidone , tinidazole, ornidazole are used for the treatment of the disease. The most widely used treatment protocols employ metronidazole given 3 times per day for 3-5 days ${ }^{4-8}$. In one study, the therapeutic effects of mebendazole and metronidazole were compared on giardiasis. Mebendazole as $200 \mathrm{mg}$, 2 times a day for 5 days and metronidazole as 250 mg, 3 times a day for 5 days used in treatment of

\footnotetext{
* To whom all correspondence should be addressed. Tel.: 00989125249008;

E-mail: moses.ahmadi@yahoo.com
}

giardiasis. In this investigation Therapeutic effects of mebendazole was stronger than metronidazole ${ }^{5-}$ 13 .

In another study, the therapeutic effects of albendazole and metronidazole were compared on giardiasis .Albendazole as $400 \mathrm{mg}$ daily was effective on giardiasis $(97 \%)^{6}$. In another study in India, average response to treatment, were faster with albendazole than metronidazole ${ }^{11}$.

Recent evidence for the anti-giardial activity of albendazole raises the prospect of safe and effective treatment of children in endemic areas if the drug is used with complementary health and hygiene education programmes ${ }^{14-17}$.

\section{MATERIALSAND METHODS}

In this study, we examined four groups of patients. The first group consists of high school students in Tehran (A). The second group consists of students of Tehran Teachers Training Center (B). The third group was patients admitted to the Infectious Diseases Clinics of Shahid behishti medical university (C), the fourth group consisted 
of patients attending private clinics (D) . After informed consent was obtained, a detailed medical history was taken from each patient and physical examination was performed. For the demonstration of trophozoites or cysts in the stool, 3 stool samples were obtained. Stool samples were assessed for giardiasis by the saline-Lugol formalin ethyl acetate concentration and trichrome staining methods ${ }^{3}$. Only patients with G.intestinalis cysts or trophozoites in a sample were eligible for enrollment in the study. To evaluate the effectiveness of the therapy, 3stool samples from all cases were examined on 6 - 10 days following completion of treatment by the same laboratories. Clinical symptoms were also evaluated.

\section{Study medication}

The metronidazole and mebendazole and albendazole tablets were placed in separate packages. As none of the doctors were unaware of the type of pills in packages . Patients in each groups $(A, B, C, D)$ were randomized to receive albendazole $400 \mathrm{mg} / \mathrm{d}$ for $5 \mathrm{~d}$ or metronidazole 250 $\mathrm{mg}$ thrice daily for $5 \mathrm{~d}$. or mebendazole $200 \mathrm{mg}$ twice daily for $5 \mathrm{~d}$.

\section{Cases}

263 patients- aged 11- 47 years participated in this study. Of these, 80 were excluded from the study for various reasons. 51 of these patients were high school students , 70 people were college students , 13 were employee and 30 were workers. 17 of these patients, were illiterate, 51 were elementary School ,115 were high school or higher. Of the 183 stool sample positive patients, 153 cases were positive for giardia cysts and 30 cases were positive for giardia trophozoites. Of these 70 cases were symptomatic (38/25\% ) and 113 cases were asymptomatic $(61 / 75 \%)$. All trophozoite positive patients were symptomatic . These symptoms include : cramping, bloating, diarrhea , nausea , vomiting , foul smelling stool , weight loss .

\section{Statistical analysis}

The data were evaluated by SPSS for Windows 6.1. Differences between the ratios in qualitative variables were evaluated by Yates' corrected chi-square test . Differences with $\mathrm{p}<$ 0.05 were considered to be statistically significant.

\section{RESULTS}

In this study, 55 cases treated with mebendazole, 61 cases treated with albendazole and 67 cases treated with metronidazole . Eradication of the parasites (i.e., no G. Lamblia cysts and $\mathrm{D}$ or trophozoites present) was achieved in 49 cases treated with mebendazole, and 57 cases treated with albendazole and 64 cases treated with metronidazole (Table 2). The final results showed that albendazole (93\%) and mebendazole ( $89 \%$ ) and metronidazole (95.5\%) have similar therapeutic effects on giardiasis. By Using a Chi- squire test that therapeutic success in each therapeutic groups was not statistically significant .

\section{Therapeutic side effects}

In this study, 26 cases of metronidazole recipients (39\%) and 12 cases of albendazole recipients (19.7\%) and 15 cases of mebendazole

Table 1. The age distribution of patients according to sex

\begin{tabular}{lccc}
\hline Age in years & Male & Female & All \\
\hline $10-14$ & 9 & 20 & 29 \\
$15-19$ & 37 & 17 & 54 \\
$20-24$ & 37 & 3 & 40 \\
$25-29$ & 13 & 4 & 17 \\
$30-34$ & 10 & 1 & 11 \\
$35-39$ & 12 & 4 & 16 \\
$40-44$ & 8 & 4 & 12 \\
45 and above & 3 & 1 & 4 \\
All & 129 & 54 & 183 \\
\hline
\end{tabular}

Table 2. Parasite eradication following treatment with albendazole or metronidazole or mebendazole

\begin{tabular}{lccc}
\hline Groups & Albendazole & Mebendazole & Metronidazole \\
\hline parasite-free patients & 57 & 49 & 64 \\
parasite - positive patients & 4 & 6 & 3 \\
All & 61 & 55 & 67 \\
\hline
\end{tabular}

$\mathbf{x} 2=1 / 9 \quad \mathrm{df}=2 \quad \mathrm{P}=$ non significant


SHOKOUH \& AHMADI, Biosci., Biotech. Res. Asia, Vol. 13(2), 961-965 (2016)

Table 3. Distribution of drugs side effects in each therapeutic groups

\begin{tabular}{lccc}
\hline Groups & Albendazole & Mebendazole & Metronidazole \\
\hline Complications-free patients & 49 & 40 & 41 \\
Complications-positive patients & 12 & 15 & 26 \\
All & 61 & 55 & 67 \\
\hline x2 $=9 / 1 \quad$ df $=2 \quad \mathrm{P}<0 / 01$ & & &
\end{tabular}

Table 4. Percentage distribution of drug side effects in each therapeutic groups

\begin{tabular}{|c|c|c|c|c|c|c|}
\hline \multirow{2}{*}{$\begin{array}{l}\text { Groups } \\
\text { Side effects }\end{array}$} & \multicolumn{2}{|c|}{ Albendazole } & \multicolumn{2}{|c|}{ Mebendazole } & \multicolumn{2}{|c|}{ Metronidazole } \\
\hline & Number & Percent & Number & Percent & Number & Percent \\
\hline Malase & 3 & 5 & 3 & 5.5 & 3 & 4.5 \\
\hline Nasea & 3 & 5 & 3 & 5.5 & 11 & 16.4 \\
\hline Vomiting & 0 & 0 & 0 & 0 & 9 & 13.4 \\
\hline Metallic & 0 & 0 & 0 & 0 & 9 & 13.4 \\
\hline taste & 4 & 6.5 & 5 & 9 & 4 & 6 \\
\hline Dizziness & 2 & 3.3 & 2 & 3.6 & 3 & 4.5 \\
\hline HeadacheOthers & 3 & 5 & 6 & 11 & 5 & 7.4 \\
\hline
\end{tabular}

recipients (27.3\%) had a drug side effects. By Using a Chi- squire test that was statistically significant $(\mathrm{P}<0 / 01)$.

\section{DISCUSSION}

The mainstay of treatment of giardiasis is metronidazole, It has been widely used to treat giardiasis in humans ${ }^{1,2}$ and often causes side effects such as nausea, metallic taste, dizziness and headache ${ }^{8}$. In addition, this drug is a known mutagen in bacteria ${ }^{23,24}$. it is genotoxic to human cells ${ }^{25,25}$ and it has been shown to be carcinogenic in animal models ${ }^{25,26}$. However, there is no evidence showing metronidazole is also carcinogenic in humans ${ }^{25}$. Typically, metronidazole is administered in doses of $250 \mathrm{mg} 3$ times a day for 5-7 days for adults and $15 \mathrm{mg} / \mathrm{kg} 3$ times a day for 5-7 days in children. An extended period of time for the treatment of giardiasis may be associated with frequent side effects.

The other consideration when using metronidazole is the consumption of alcohol that may be associated with disulfiram-like reaction (nausea, vomiting, flushing, and tachycardia) and should be avoided by patients during systemic metronidazole therapy and for at least 24 hours after completion of treatment.

Resistance of $\mathrm{G}$. duodenalis strains to metronidazole has been reported both in vitro and in vivo. Misra et al. ${ }^{15}$ reported a $100 \%$ cure rate in groups treated with either metronidazole or albendazole, while the other reports show an effectiveness of $72.7-100 \%$ for metronidazole and $77-97 \%$ for albendazole.

Sadjjadi et $a l^{21}$, who used $200 \mathrm{mg}$ mebendazole thrice daily for $5 \mathrm{~d}$-which resulted in somewhat higher cure rates [43 out of 50 (86\%)] and found a frequency comparable to that obtained by using a 7-d course of metronidazole, it was 45 out of 50 (90 per cent) with no statistical difference between the two groups .

Roberto Cañete et al.,22 also used $200 \mathrm{mg}$ of mebendazole taken three times per day or quinacrine $\quad[2 \mathrm{mg} / \mathrm{kg}$ bodyweight $]$ tid, both for five days. The frequency of cure was higher for quinacrine (83.6\%) than for mebendazole (78.7\%), the difference was not statistically significant $(P>$ $0.05)$. Adverse events were reported more in the quinacrine group $(P<0.05)$, all of them transient and self-limiting. In most studies, albendazole was as good as metronidazole or better ${ }^{29}$.

Given the multiple side effects of metronidazole and some resistant G. duodenalis 
strains to metronidazole and effective and with less side effects drugs other than metronidazole for treating G. duodenalis, using that drugs as an alternative would be reasonable .

In the present study, the final results showed that albendazole (93\%) and mebendazole ( 89\% ) and metronidazole (95.5\%) have similar therapeutic effects on giardiasis . Advantage of this study is use of three anti-giardia drugs ( albendazole , mebendazole , metronidazole ) for the treatment of giardiasis and evaluation of their efficacies and side effects. There are some limitations in the present study. First, use of different laboratories, clinics and Colleagues can have undesirable Influence on the results. Second, Clinical and laboratory evaluation was performed on 6 - 10 days following completion of treatment only once. So after that, there was no data about symptoms and signs of patients (recurrent of diseases).

Considering the high rate of side effects from metronidazole therapy for giardiasis, combined with the global emergence of resistant strains of G. duodenalis, and similar therapeutic effects of these three drugs on giardiasis, we suggest effective alternative treatments such as albendazole for Giardia infections .

\section{REFERENCES}

1. Adam RD, Biology of Giardia labmlia. Clin Microbiol Rev 2001; 14: 447-475.

2. Farthing MJ., Diarrhoeal disease: current concepts and future challenges. Pathogenesis of giardiasis. Trans R Soc Trop Med Hyg 1994; 3: 17-21.

3. Flanagan PA., Giardia-diagnosis, clinical course and epidemiology. A review. Epidemiol Infect 1992; 109: 1-22.

4. Gardner TB, Hill DR, Treatment of giardiasis. Clin Microbiol Rev 2001; 14: 114-128.

5. Liu LX, Weller PF.Antiparasitic drugs. $N$ Engl $J$ Med 1996; 334: 1178-1185.

6. Noori S.Dawood AL-Waili and Noori U.Hassan. Mebendazole in giargia infecgtion a comparative study with metronidazole. J Infectious diseases 1992; 165:1170-1.

7. Gardner TB, Hill DR, Treatment of giardiasis. Clin Microbiol Rev 2001; 14: 114-128.

8. Hall A, Nahar Q, Albendazole as a treatment for infections with Giardi duodenalis in children in Bangladesh. Trans R Soc Trop Med Hyg 1993a,b;
87: 84-86.

9. Bassily S, Farid Z, Mikhail JW, Kent DC, Lehman JS, The treatment of Giardia lamblia infection with mepacrine, metronidazole and furazolidone. J Trop Med Hyg 1970; 73:15-18.

10. Jokipii L, Jokipii AMM, Comparison of four dosage schedules in the treatment of giardiasis with metronidazole. Infection 1978; 6: 92-94.

11. Kavousi S, Giardiasis in infancy and childhood: a prospective study of 160 cases with comparison of quinacrine (AtabrineH) and metronidazole (FlagylH).Am J Trop Med Hyg 1979; 28: 19-23.

12. Jokipii L, Jokipii AM, Comparison of four dosage schedules in the treatment of giardiasis with metronidazole. Infection 1978; 6: 92-94.

13. Rastegar-Lari A, Salek-Moghaddam A, Singledose secnidazole versus 10-day metronidazole therapy of giardiasis in Iranian children. $J$ Trop Pediatr 1996; 42: 184-185.

14. Bulut BU, Gu"lnar SB, Aysev D, Alternative treatment protocols in giardiasis: a pilot study. Scand J Infect Dis 1996; 28: 493-495.

13. Sadjjadi SM, Alborzi AW, Mostovfi H. Comparative clinical trial of mebendazole and metronidazole in giardiasis of child-dren. Journal of tropical pediatrics, 2001; 47(3):176-8.

15. Misra PK et al. A comparative clinical trial of albendazole versus metronidazole in children with giardiasis. Indian pediatrics, 1995; 32(7):779-82.

16. Baqai R, Zuberi SJ, Qureshi H, Ahmed W, Hafiz S, Efficacy of albendazole in giardiasis. East Meditter Health J 2001; 7: 787-790.

17. - Alizadeh A, Ranjbar M, Kashani KM, Taheri MM, Bodaghi M, Albendazole versus metronidazole in the treatment of patients with giardiasis in the Islamic Republic of Iran. East Meditter Health J 2006; 12: 548-554.

18, Karabay O, Tamer A, Gunduz H, Kayas D, Arinc $\mathrm{H}$, et al., Albendazole versus metronidazole treatment of adult giardiasis: An open randomized clinical study. World J Gastroenterol 2004; 10: 1215-1217.

19. Yereli K, Balciogథlu IC, Ertan P, Limoncu E, Onag $₫$ A, Albendazole as an alternative therapeutic agent for childhood giardiasis in Turkey. Clin Microbiol Infect 2004; 10: 527529.

20. Dutta AK, Phadke MA, Bagade AC et al. A randomised multicentre study to compare the safety and efficacy of albendazole and metronidazole in the treatment

21. Sadjjadi SM, Alborzi AW, Mostovfi H. Comparative clinical trial of mebendazole and metronidazole in giardiasis of child-dren. Journal 
of tropical pediatrics, 2001; 47(3):176-8.

22. Roberto Cañete, Angel A Escobedo, María E González and Pedro Almirall, Randomized clinical study of five days apostrophe therapy with mebendazole compared to quinacrine in the treatment of symptomatic giardiasis in children W Cantelli-Forti G, Aicardi G, Guerra MC, Barbaro AM, Biagi GL 1983.

23. Mutagenicity of a series of 25 nitroimidazoles and two nitrothiazoles in Salmonella typhimurium. Teratog Carcinog Mutagen 2004; 3: 51-63.

24. De Méo M, Vanelle P, Bernadini E, Laget M, Maldonado J, et al., Evaluation of the mutagenic and genotoxic activities of 48 nitroimidazoles and related imidazole derivatives by the Ames test and the SOS chromotest. Environ Mol Mutagen 1992; 19: 167-181.

25. Krause JR, Ayuyang HQ, Ellis LD, Occurrence of three cases of carcinoma in individuals with Crohn's disease treated with metronidazole.Am
J Gastroenterol 1985; 80: 978-982.

26. Bendesky A, Mene'ndez D, Ostrosky-Wegman $\mathrm{P}$, Is metronidazole carcinogenic? Mutat Res 2002; 511: 133-144.

27. Tillonen J, Va“keva“" inen S, Salaspuro V, Zhang Y, Rautio M, et al., Metronidazole increases intracolonic but not peripheral blood acetaldehyde in chronic ethanol-treated rats. Alcohol Clin Exp Res 2000; 24: 570-575.

28. Jang GR, Harris RZ, Drug interactions involving ethanol and alcoholic beverages. Expert Opin Drug Metab Toxicol 2007; 3: 719-731.

29. Chan Del Pino M, Cueva Cornejo L, Troyes Rivera L. Comparación de Albend-dazol con nitrofuranos y nitroimidazoles en el tratamiento de giardiasis en niños [Comparative study of albendazole vers-sus nitrofurazones and nitroimidazoles in the treatment of giardiasis in children.] Revista de gastroenterología del Perú, 1999;19(2):95-108. 